\title{
Lithography-free microfabrication of AIGaN/GaN 2DEG strain sensors using laser ablation and direct wire bonding
}

\author{
Karen M. Dowling ${ }^{1}$, Hongyun So ${ }^{2, a)}$ Anju Toor $^{3}$, Caitlin A. Chapin ${ }^{4}$, and Debbie G. Senesky ${ }^{1,2}$ \\ ${ }^{1}$ Department of Electrical Engineering and ${ }^{2}$ Aeronautics and Astronautics, Stanford University, Stanford, CA 94305, \\ United States \\ ${ }^{3}$ Department of Mechanical Engineering, University of California, Berkeley, CA 94720, United States \\ ${ }^{4}$ Department of Mechanical Engineering, Stanford University, Stanford, CA 94305, United States
}

\begin{abstract}
This work presents a simple and rapid lithography-free (i.e., maskless) microfabrication process for strain-sensitive aluminum gallium nitride $(\mathrm{AlGaN}) / \mathrm{GaN}$ sensors. We microfabricated an AlGaN/GaN strain sensor through laser ablation of the underlying $\mathrm{Si}$ (111) substrate and direct bonding of aluminum wires to the AlGaN surface, creating a Schottky contact to the twodimensional electron gas (2DEG). We measured the sensor's current-voltage operation while displacing the center of the membrane up to $106.7 \mu \mathrm{m}$ and characterized its sensitivity at from 0.5 to $2 \mathrm{~V}$ bias (i.e., 5 to $100 \mathrm{nA} / \mu \mathrm{m}$ ). This work advances the development of $\mathrm{AlGaN} / \mathrm{GaN}$-onSi microelectronics (e.g., pressure sensors, accelerometers, and gyroscopes) using the simplified fabrication process, which eliminates lithography, metallization, and etching, and reduces the manufacturing time (5 min) and cost, as well as the need for cleanroom environments.
\end{abstract}

Keywords: Gallium nitride, Microfabrication, Strain sensor, Laser ablation, Direct wire bonding

a) Author to whom correspondence should be addressed. E-mail: hyso@ stanford.edu. 


\section{Introduction}

Microelectronics based on aluminum gallium nitride ( $\mathrm{AlGaN}$ ) and $\mathrm{GaN}$ heterostructures have gained interest for various sensing applications such as strain [1,2], pressure [3,4], inertial [5], chemical [6], and optical sensors [7,8] due to their higher sensitivity and extended operation temperature by wide bandgap properties. Among such devices, AlGaN/GaN-based mechanical sensors have particularly emerged because the conductive two-dimensional electron gas (2DEG) formed at the $\mathrm{AlGaN} / \mathrm{GaN}$ interface is highly responsive to external stimuli $[9,10]$. The majority of $\mathrm{AlGaN} / \mathrm{GaN}$ mechanical sensors typically use suspended membrane $[2,3,11]$ or cantilever [1] elements with metal alloys for Ohmic and Schottky contacts. In general, such devices scheme requires multiple microfabrication steps including thin film deposition, lithography, dry/wet etching, metallization, and annealing. In addition, fabricated devices are needed to be packaged separately on ceramic chip carriers. However, this multiple microfabrication steps and packaging process lead to high cost, a lot of time, and complexity of overall process. Consequentially, a development of simple and rapid microfabrication/packaging techniques is required for the fabrication of various microelectronics. In this work, we demonstrate a facile, rapid, and reliable microfabrication technique using direct laser ablation and direct wire bonding $[7,12]$ to create $\mathrm{AlGaN} / \mathrm{GaN}$ strain sensors (suspended membrane type) in less than 5 minutes. The silicon ( $\mathrm{Si}$ ) substrate was quickly etched away using the laser ablation, which is much faster etching process compared to conventional Si dry/wet etching, to release membrane structure. The backside $\mathrm{Si}$ etching was achieved without any photolithography processes including photoresist coating, baking, photoresist development, and backside alignment. In addition, the direct bonding between suspended $\mathrm{AlGaN} / \mathrm{GaN}$ membrane and chip carrier enables simultaneous metallization and packaging processes that eliminate tedious metallization process (i.e., lift-off). 
(a)

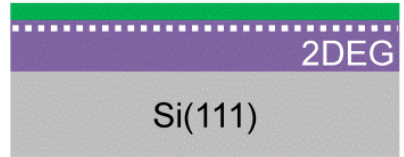

(b)

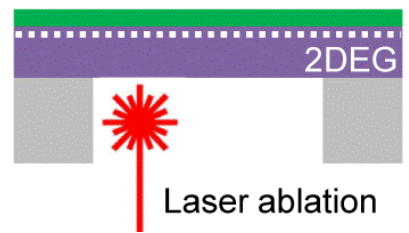

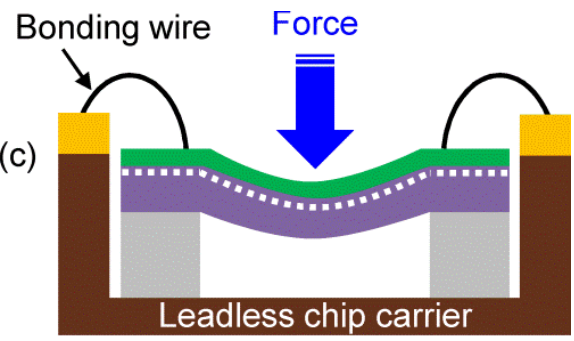

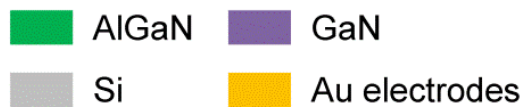

Fig. 1. Schematic of $\mathrm{AlGaN} / \mathrm{GaN}$ strain sensors using a combination of laser ablation etching and direct wire bonding architectures. (a) Singulation of AlGaN/GaN-on-Si die, (b) membrane suspension using laser ablation, and (c) aluminum wire bonding between $\mathrm{AlGaN}$ surface and leadless chip carrier.

\section{Experimental method}

A schematic of our simple fabrication process is shown in Fig. 1. AlGaN/GaN-on-Si wafer (DOWA, 2DEG mobility of $\sim 1400 \mathrm{~cm}^{2} / \mathrm{V} \cdot \mathrm{s}$ ) was singulated into $5 \mathrm{~mm} \times 5 \mathrm{~mm}$ die (Fig. 1a). Then a circular diaphragm (3.5 mm diameter) of the underlying Si substrate was etched using laser ablation (DPSS Samurai UV Laser) (Fig. 1b). The laser was operated at $3 \mathrm{~W}$ at $30 \mathrm{kHz}$ pulses, 30 passes, $200 \mathrm{~mm} / \mathrm{s}$ scribe speed, $25 \mu \mathrm{m}$ scribe spacing, and cross hatch cut path, completed in 200 seconds. The etched die was rinsed with acetone and isopropyl alcohol to remove chip debris. The die was then attached with polyimide tape to a ceramic leadless chip carrier (LCC) and directly wire-bonded (ultrasonic power of $460 \mathrm{~mW}$ for $30 \mathrm{~ms}$ ) using aluminum bonding wire (25.4 $\mu \mathrm{m}$ diameter) [7] (Fig. 1c). The fabricated device was tested under various displacements using a micromanipulator (Signatone S-M40) with a small tip, centered over the diaphragm. Force was applied through vertical displacements at $1 / 48^{\text {th }}$ turn of the knob $(\sim 13.3$ $\mu \mathrm{m})$. Figures $2 \mathrm{a}$ and $2 \mathrm{~b}$ show the experimental testing setup and optical image of packaged $\mathrm{AlGaN} / \mathrm{GaN}$ die on the LCC used in this study, respectively. A small tip on the end of the micromanipulator was centered over the packaged AlGaN/GaN strain sensor. The tip was slowly moved down toward the center of the membrane while measuring the current-voltage response in 

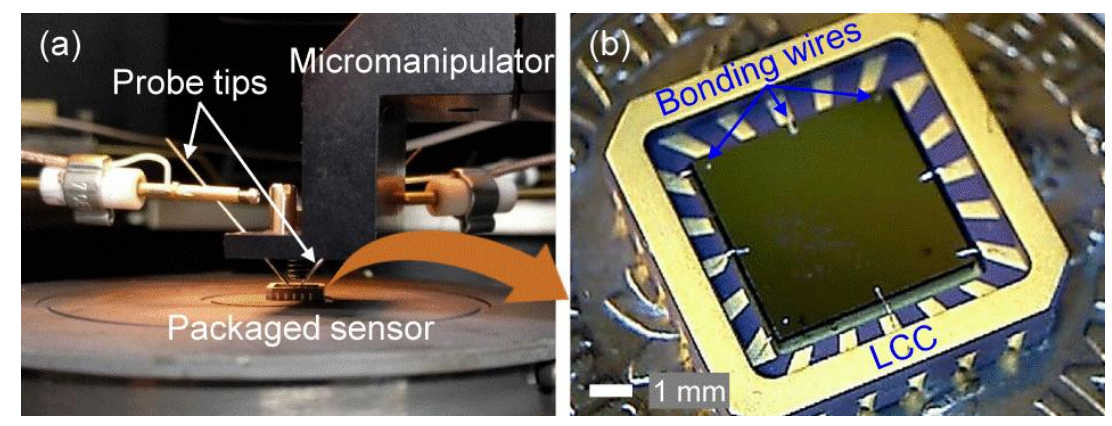

Fig. 2. (a) Image of experimental setup for strain transduction measurements and (b) optical image of packaged AlGaN/GaN die on ceramic leadless chip carrier (LCC).

a range of voltage $\left(\mathrm{V}_{\text {bias }}\right)$ from 0 to $2 \mathrm{~V}$. We added $1 / 48^{\text {th }}$ of a turn and took sequential currentvoltage measurements until the displacement reaches $107.6 \mu \mathrm{m}$ over which the membrane was broken. To characterize the sensors transient and reliable response, the change of current with respect to time was also monitored with varied bias voltages. This measurement was conducted by alternatively applying and releasing displacement.

\section{Results and discussion}

Figures 3a shows an optical image of $3.5 \mathrm{~mm}$ diameter cavity etched by laser ablation of the underlying $\mathrm{Si}$ substrate. To characterize the surface roughness, etched surface was visually investigated using 3D non-contact confocal microscope (S-neox, Sensofar) and it showed RMS surface roughness of $21.34 \mu \mathrm{m}$, as shown in Fig. 3b. Figures 3c and 3d show a cross-sectional scanning electron microscope (SEM) image of suspended AlGaN/GaN diaphragm (thickness of $\sim 190 \mu \mathrm{m}$ ) and Al wire directly bonded between the LCC and AlGaN surface, respectively. The physically stable and electrically reliable metal contact was achieved using a direct wire bonding between the LCC and sensing surface. This simultaneous fabrication and packaging process took only approximately $5 \mathrm{~min}$ (with 1 hour of preparation time) whereas several hours and photolithography masks are needed in conventional microfabrication and packaging methods. 

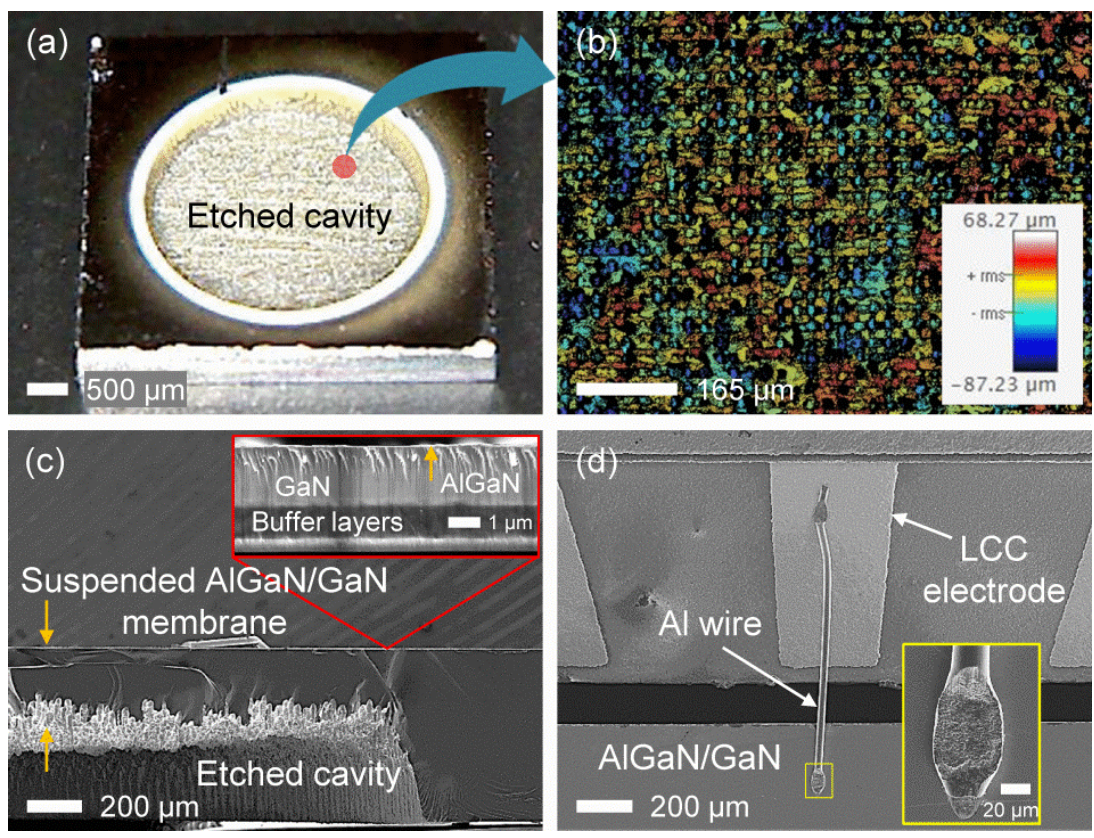

Fig. 3. (a) Optical image of a $3.5 \mathrm{~mm}$ diameter cavity etched by laser ablation of the underlying Si substrate, (b) confocal contour of etched surface indicating RMS surface roughness of $21.34 \mu \mathrm{m}$, (c) cross-sectional SEM image of suspended $\mathrm{AlGaN} / \mathrm{GaN}$ membrane after laser ablation etching, and (d) aluminum wires directly bonded between $\mathrm{LCC}$ and $\mathrm{AlGaN}$ surface for electrical connection.

To characterize the fabricated strain sensors, we applied different displacements with a micromanipulator and measured the current-voltage response. Figure 4 shows the change in current passing through the 2DEG with respect to applied displacement (i.e., strain). External strain through applied displacement induces additional piezoelectric polarization of the 2DEG [13], changes in surface traps [14], and alters the Schottky barrier height [15]. Therefore, there was an increase in current when the membrane was gradually deflected from $13 \mu \mathrm{m}$ to $106.7 \mu \mathrm{m}$. It should be noted that the current came back to the base current (i.e., dashed line in Fig. 4) when the stain was completely released, indicating a stable and reversible sensor's operation. Figure 5 shows the change of current $(\Delta \mathrm{I})$ with respect to applied stain under different operation voltages. To estimate the sensitivity of the sensor, a linear fitting curve was employed on each data. The measured data are in good agreement with linear fitting curves, as seen in Fig. 5. Table 1 summarizes the calculated sensitivity (in $\mathrm{nA} / \mu \mathrm{m}$ unit) with the coefficient of determination $\left(\mathrm{R}^{2}\right)$ 


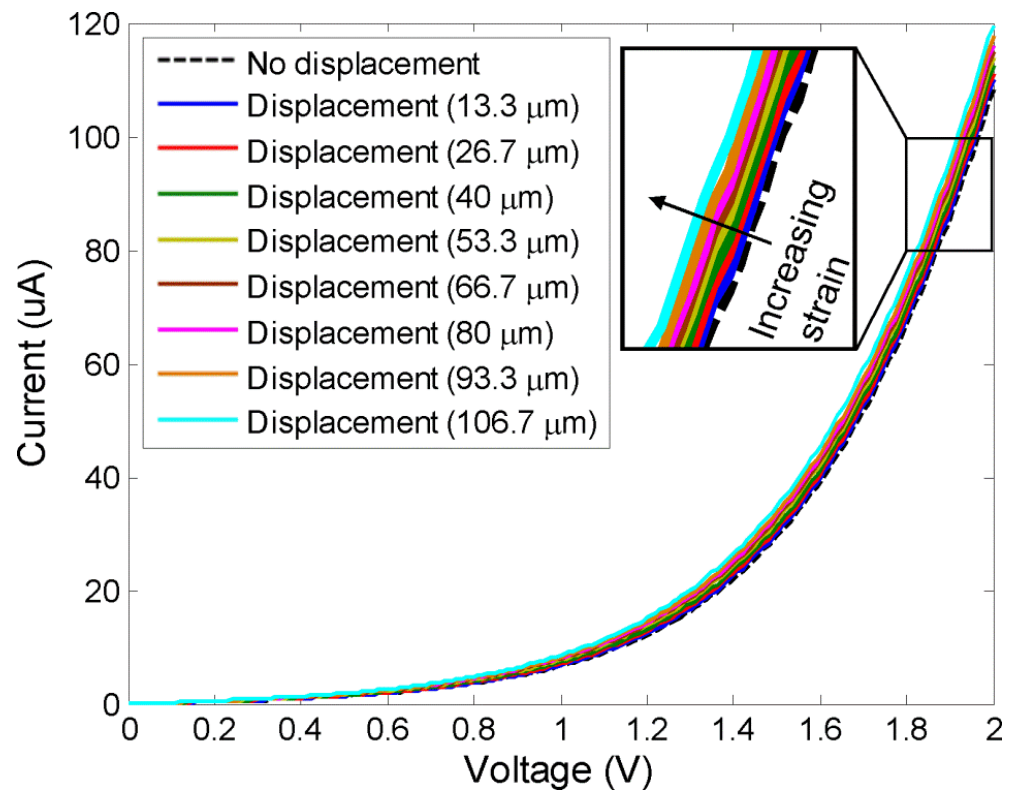

Fig. 4. Current change of the fabricated $\mathrm{AlGaN} / \mathrm{GaN}$ strain sensor under different applied displacement.

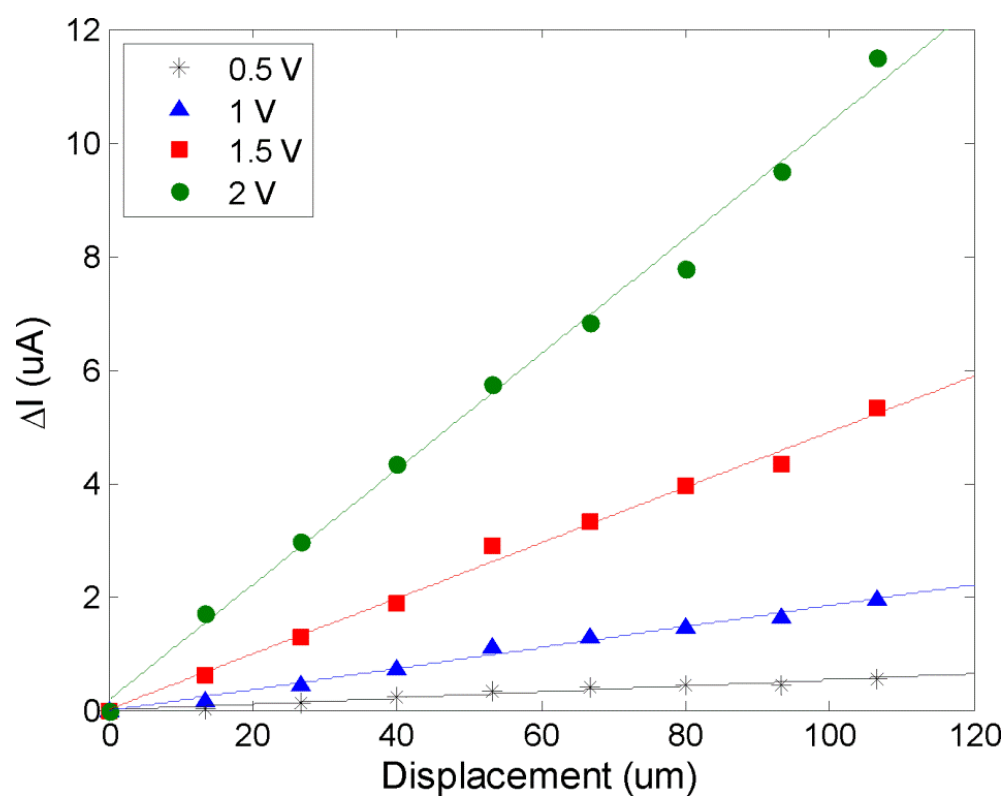

Fig. 5. Change of current and linear fitting curves with respect to various displacements under different operation voltages.

values of linear fitting curves. The $\mathrm{R}^{2}$ values around 0.96 to 0.99 for four different linear fitting curves showed the proportional (linear) trend of current change with respect to the applied 
displacements. In addition, the sensitivity increases with an increase in $\mathrm{V}_{\text {bias}}$, which is a general trend of devices using a Schottky contact [16-18].

Table 1 Calculated sensor's sensitivity and coefficient of determination values using linear curve fitting method.

\begin{tabular}{ccc}
\hline Applied bias $(\mathrm{V})$ & Sensitivity $(\mathrm{nA} / \mu \mathrm{m})$ & $\mathrm{R}^{2}$ \\
\hline 0.5 & 5.3 & 0.966 \\
1 & 18.5 & 0.991 \\
1.5 & 48.9 & 0.994 \\
2 & 101.6 & 0.994 \\
\hline
\end{tabular}

To characterize transient response of the fabricated sensor, the real-time current change was monitored with different levels of displacement applied and released alternatively, as shown in Fig. 6. It should be noted that the base current at high $\mathrm{V}_{\text {bias }}$ (i.e., 2 and $3 \mathrm{~V}$ ) was drifted at the beginning because of initial discharging from transients when device was first turned on. Once these transients were settled (stable), the current-voltage response was returned to the original base level upon release of the displacement, as shown in Fig. 6, demonstrating stable and reversible operation of the fabricated $\mathrm{AlGaN} / \mathrm{GaN}$ strain sensor. There was some variation in the base current due to the manual placement of wire bonds and AlGaN/GaN membrane thickness variation due to laser focus during the ablation etching process. In addition, since this microfabrication technique relies on the fabrication of Schottky diodes, variations in surface states may have a larger impact on the device sensitivity than high-electron mobility transistors (HEMTs) architecture. Nevertheless, this prototyping method enables low cost testing for studying 2DEG transduction properties and rapid customization for GaN-on-Si microelectronics products without cleanroom infrastructure. 


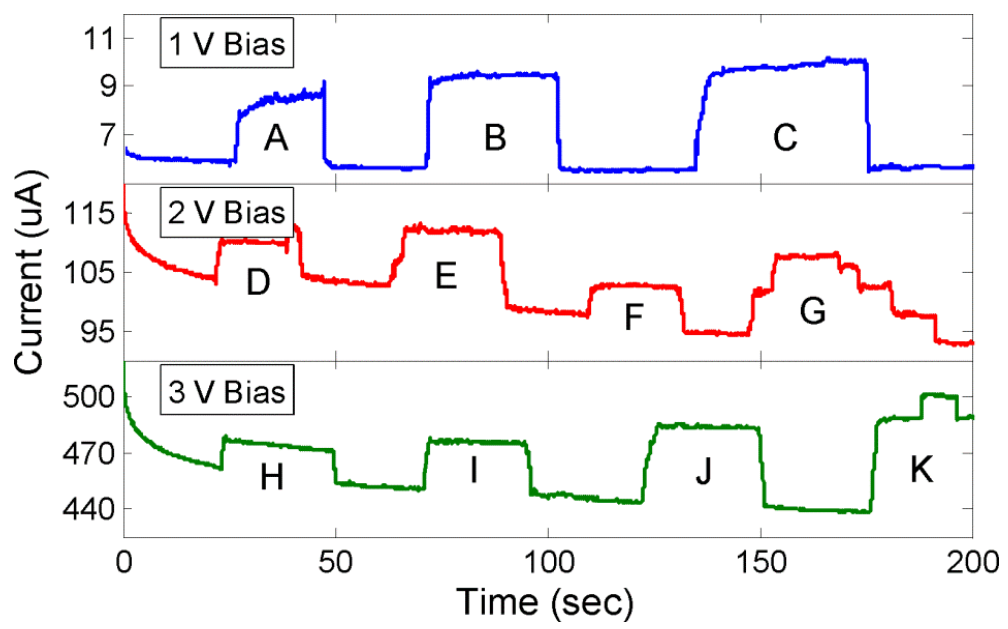

Fig. 6. Transient current response for the strain sensor under different bias voltages $(1,2$, and $3 \mathrm{~V})$ with different levels of displacement applied and released alternatively. $26.7 \mu \mathrm{m}$ steps $=\mathrm{A}, \mathrm{D}, \mathrm{F}, \mathrm{H} ; 53.3 \mu \mathrm{m}$ steps $=\mathrm{B}, \mathrm{E}, \mathrm{G}, \mathrm{I} ; 80$ $\mu \mathrm{m}$ steps $=\mathrm{C}, \mathrm{J} ; 106.7 \mu \mathrm{m}=\mathrm{K}$.

\section{Conclusions}

In summary, this study reports the facile and rapid microfabrication technique for AlGaN/GaN strain sensors. The laser ablation was used for etching Si substrate and release AlGaN/GaN membrane within a short period time. The direct bonding of $\mathrm{Al}$ wires on AlGaN surface was achieved for simple electrical connection between the LCC and sensors. The overall fabrication process was completed within 5 min, which is significantly faster than conventional microfabrication processes. This prototyping method enables testing GaN-on-Si microelectronics devices before investing in a costly wafer-scale process, and studying $\mathrm{GaN}$ in laboratories without cleanroom facilities.

\section{Conflict of Interest}

The authors declare no competing financial interest. 


\section{Acknowledgements}

This work was supported in part by the National Science Foundation Engineering Research Center for Power Optimization of Electro Thermal Systems under Grant EEC-1449548 and in part by the National Science Foundation Graduate Research Fellowship under Grant DGE114747. The authors are grateful for support from the Stanford Nanofabrication Facility (SNF) and Stanford Nano Shared Facilities (SNSF) at Stanford University.

\section{References}

[1] B.S. Kang, S. Kim, J. Kim, F. Ren, K. Baik, S.J. Pearton, B.P. Gila, C.R. Abernathy, C.C. Pan, G.-T. Chen, J.-I. Chyi, V. Chandrasekaran, M. Sheplak, T. Nishida, S.N.G. Chu, Effect of external strain on the conductivity of $\mathrm{AlGaN} / \mathrm{GaN}$ high-electron-mobility transistors, Appl. Phys. Lett. 83 (2003) 4845-4847.

[2] M. Eickhoff, O. Ambacher, G. Krötz, M. Stutzmann, Piezoresistivity of AlxGa1-xN layers and AlxGa1-xN/GaN heterostructures, J. Appl. Phys. 90 (2001) 3383-3386.

[3] B.S. Kang, S. Kim, F. Ren, J.W. Johnson, R.J. Therrien, P. Rajagopal, J.C. Roberts, E.L. Piner, K.J. Linthicum, S.N.G. Chu, K. Baik, B.P. Gila, C.R. Abernathy, S.J. Pearton, Pressure-induced changes in the conductivity of AlGaN/GaN high-electron mobilitytransistor membranes, Appl. Phys. Lett. 85 (2004) 2962-2964.

[4] M.J. Edwards, E.D. Le Boulbar, S. Vittoz, G. Vanko, K. Brinkfeldt, L. Rufer, P. Johander, T. Lalinský, C.R. Bowen, D.W.E. Allsopp, Pressure and temperature dependence of $\mathrm{GaN} / \mathrm{AlGaN}$ high electron mobility transistor based sensors on a sapphire membrane, Phys. Status Solidi C. 9 (2012) 960-963.

[5] J. Tang, T. Liang, Q. Zhang, Y. Wang, W. Shi, J. Wang, J. Xiong, The research of piezoresistive effect in different temperature based on AlGaN/GaN HEFT-microaccelerometer, in: 2010 10th IEEE Int. Conf. Solid-State Integr. Circuit Technol., IEEE, 2010: pp. 1542-1544.

[6] K. Matsuo, N. Negoro, J. Kotani, T. Hashizume, H. Hasegawa, Pt Schottky diode gas sensors formed on $\mathrm{GaN}$ and $\mathrm{AlGaN} / \mathrm{GaN}$ heterostructure, Appl. Surf. Sci. 244 (2005) 273-276.

[7] H. So, D.G. Senesky, Rapid fabrication and packaging of AlGaN/GaN high-temperature ultraviolet photodetectors using direct wire bonding, J. Phys. D. Appl. Phys. 49 (2016) 285109. 
[8] H. So, J. Lim, D.G. Senesky, Continuous v-grooved AlGaN/GaN surfaces for hightemperature ultraviolet photodetectors, IEEE Sens. J. 16 (2016) 3633-3639.

[9] M. Eickhoff, J. Schalwig, G. Steinhoff, O. Weidemann, L. Görgens, R. Neuberger, M. Hermann, B. Baur, G. Müller, O. Ambacher, M. Stutzmann, Electronics and sensors based on pyroelectric AlGaN/GaN heterostructures - Part B: Sensor applications, Phys. Status Solidi c. 0 (2003) 1908-1918.

[10] S.J. Pearton, B.S. Kang, S. Kim, F. Ren, B.P. Gila, C.R. Abernathy, J. Lin, S.N.G. Chu, GaN-based diodes and transistors for chemical, gas, biological and pressure sensing, J. Phys. Condens. Matter. 16 (2004) R961-R994.

[11] T. Lalinský, P. Hudek, G. Vanko, J. Dzuba, V. Kutiš, R. Srnánek, P. Choleva, M. Vallo, M. Držík, L. Matay, I. Kostič, Micromachined membrane structures for pressure sensors based on AlGaN/GaN circular HEMT sensing device, Microelectron. Eng. 98 (2012) 578581 .

[12] H. So, D.G. Senesky, $\mathrm{ZnO}$ nanorod arrays and direct wire bonding on GaN surfaces for rapid fabrication of antireflective, high-temperature ultraviolet sensors, Appl. Surf. Sci. 387 (2016) 280-284.

[13] O. Ambacher, M. Eickhoff, A. Link, M. Hermann, M. Stutzmann, F. Bernardini, V. Fiorentini, Y. Smorchkova, J. Speck, U. Mishra, W. Schaff, V. Tilak, L.F. Eastman, Electronics and sensors based on pyroelectric AlGaN/GaN heterostructures, Phys. Status Solidi c. (2003) 1878-1907.

[14] A.S. Yalamarthy, D.G. Senesky, Strain- and temperature-induced effects in AlGaN/GaN high electron mobility transistors, Semicond. Sci. Technol. 31 (2016) 35024.

[15] K. Yao, S. Khandelwal, F. Sammoura, A. Kazama, C. Hu, L. Lin, Piezoelectricity-induced schottky barrier height variations in $\mathrm{AlGaN} / \mathrm{GaN}$ high electron mobility transistors, IEEE Electron Device Lett. 36 (2015) 902-904.

[16] Y.S. Zhou, R. Hinchet, Y. Yang, G. Ardila, R. Songmuang, F. Zhang, Y. Zhang, W. Han, K. Pradel, L. Montès, M. Mouis, Z.L. Wang, Nano-newton transverse force sensor using a vertical GaN nanowire based on the piezotronic effect, Adv. Mater. 25 (2013) 883-888.

[17] Z. Zhang, Q. Liao, X. Zhang, G. Zhang, P. Li, S. Lu, S. Liu, Y. Zhang, Highly efficient piezotronic strain sensors with symmetrical Schottky contacts on the monopolar surface of ZnO nanobelts, Nanoscale. 7 (2015) 1796-1801.

[18] K. Jenkins, V. Nguyen, R. Zhu, R. Yang, Piezotronic effect: An emerging mechanism for sensing applications, Sensors. 15 (2015) 22914-22940. 


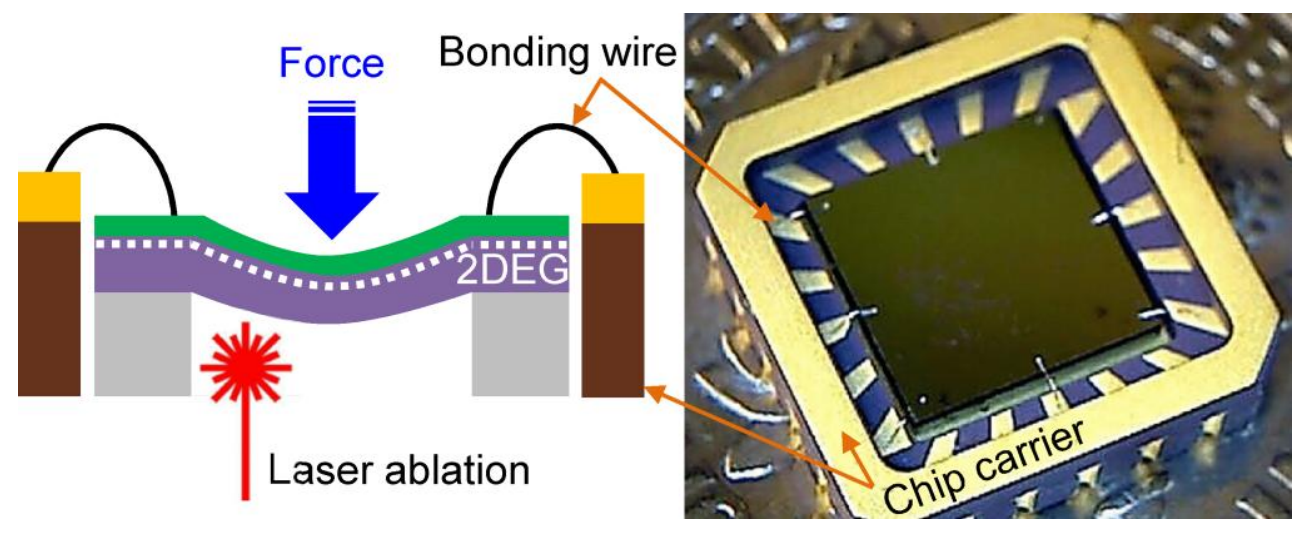

